\title{
Platelet Count to Spleen Diameter Ratio as a Predictor of Oesophageal Varices - Is It Accurate and Simple?
}

\author{
Jayachandra' ${ }^{1}$, Yogananda M.N.2, Chetan V. ${ }^{3}$, Rakshit R. Desai4, \\ Arjun P. Chandrashekar ${ }^{5}$, Jagadeesha S.G. ${ }^{6}$ \\ 1, 2, 3, 4, 5, 6 Department of Internal Medicine, Bangalore Medical College and Research Institute, \\ Bangalore, Karnataka, India.
}

\section{ABSTRACT}

\section{BACKGROUND}

All patients diagnosed with liver cirrhosis are screened using upper gastrointestinal endoscopy to detect oesophageal varices. Prophylactic measures are started to prevent possible complications. In order to decrease the increasing burden that endoscopy units will have to bear, new methods have been proposed as alternatives to conventional endoscopy for the non-invasive or minimally invasive diagnosis of oesophageal varices. In this study we aimed at using platelet / spleen diameter ratio for predicting the presence of oesophageal varices.

\section{METHODS}

In a cross-sectional study conducted among fifty newly diagnosed patients of portal hypertension. Relevant clinical parameters were assessed which included splenomegaly, ascites, laboratory parameters like haemoglobin, platelet count, prothrombin time, serum bilirubin, albumin and ultrasonographic parameters like spleen size and ascites. All patients underwent screening with upper gastrointestinal endoscopy. Platelet count to spleen diameter ratio was calculated for all patients. For the purpose of the study, patients were designated into two groups, with or without varices.

\section{RESULTS}

In this study, among 50 patients with liver cirrhosis 37 (74 \%) had varices. Males predominance was noted [42 (84\%)]. The Child Pugh score, platelet count, spleen size, platelet spleen diameter ratio was significantly different in both groups. By applying receiver operating characteristic curves, platelet count spleen diameter ratio cut off value of 1602 was obtained with a sensitivity of $78.37 \%$ and specificity of $78 \%$. The positive predictive value was $87.87 \%$ and negative predictive value was $57.94 \%$. Accuracy of this cut off value by applying receiver operating curve was 0.796 [CI $(0.655-0.937)]$.

\section{CONCLUSIONS}

The platelet count / spleen diameter ratio might not be accurate enough in predicting the presence of oesophageal varices. The evidence is not sufficient enough to replace endoscopy as screening tool for oesophageal varices in all patients with portal hypertension. It is a useful tool for predicting the presence of oesophageal varices in patients with portal hypertension non-invasively when endoscopy facilities are unavailable.

\section{KEY WORDS}

Endoscopy, Oesophageal Varices, Liver Cirrhosis, Platelet Count to Spleen Diameter Ratio, Variceal Screening
Corresponding Author:

Dr. Chetan $V$,

Junior Resident,

Department of Internal Medicine,

BMCRI, Bangalore - 560002,

Karnataka, India.

E-mail:vchetan.v1@gmail.com

DOI: $10.14260 /$ jemds/2020/848

How to Cite This Article:

Jayachandra, Yogananda MN, Chetan V, et al. Platelet count to spleen diameter ratio as a predictor of esophageal varices - is it accurate and simple? J Evolution Med Dent Sci 2020;9(51):3868-3872, DOI: $10.14260 /$ jemds/2020/848

Submission 23-06-2020,

Peer Review 28-10-2020,

Acceptance 05-11-2020,

Published 21-12-2020.

Copyright (C) 2020 Jayachandra et al. This is an open access article distributed under Creative Commons Attribution License [Attribution 4.0 International (CC BY 4.0)] 


\section{BACKGROUND}

Portal hypertension is the most common and deadly complication of chronic liver disease. It is responsible for the development of gastrointestinal varices, variceal haemorrhage, ascites, renal dysfunction, hepatic encephalopathy, hypersplenism and hepato-pulmonary syndrome. Development of oesophageal varices is a major complication of portal hypertension. ${ }^{1}$ The prevalence of oesophageal varices in patients with portal hypertension ranges from $60 \%$ to $80 \%$ and the mortality rate from variceal bleeding ranges from $17 \%$ to $57 \%$. The risk of variceal bleed is very high in patients with portal hypertension and rupture of varices is a common cause of death in cirrhosis. ${ }^{2}$

Oesophageal varices develop only after the Hepatic Venous Pressure Gradient (HVPG) has increased to at least 10 to 12 mm Hg. ${ }^{3}$ The incidence of oesophageal varices increases by nearly $5 \%$ per year and it progresses from small to large varices at a rate of approximately $5-10 \%$ per year in cirrhosis patients. The highest risk of variceal rupture is in the two years following diagnosis. ${ }^{3}$

Following the detection of oesophageal varices, the risk of variceal bleeding ranges from $20-30 \%$ within two years and a mortality of $25 \%$ to $50 \%$ within seven days of the first bleeding episode. Hence prevention of variceal bleed is the mainstay of treatment of portal hypertension. As there is enough evidence that primary prevention of variceal rupture is effective in reducing death rate, screening for oesophageal varices is recommended. ${ }^{1}$ Treatment with non-selective beta blockers in varices prophylactically that has never bled appears to reduce the incidence of bleeding by $40-50 \%$ and prolong survival. It is hence desirable to screen patients for presence of portal hypertension with endoscopy.

The American Association for the Study of liver disease single topic symposium 1996 stated that patients diagnosed with liver cirrhosis should be screened for the presence of oesophageal varices the Baveno. 3 consensus conference on portal hypertension recommended that all patients with liver cirrhosis should be screened for the presence of oesophageal varices soon after diagnosis. Many authors have suggested to repeat endoscopy at 2 - 3 years intervals in patients without varices and 1 - 2 years interval in patients with small varices and every alternate year in patients with decompensated liver disease to monitor the progression of the disease. ${ }^{3}$

Cirrhotic patients undergo frequent endoscopy for the screening of presence of oesophageal varices. In the future, this burden will increase due to greater number of patients with chronic liver disease and their improved survival. In order to decrease the burden that endoscopy units, some studies have made an attempt to identify characteristics that predict the presence of any oesophageal varices noninvasively. Cumulatively the most common result of these studies was that parameters directly or indirectly linked to portal hypertension such as decreased platelet count, enlarged spleen were predictors of the presence of oesophageal varices. ${ }^{2}$

Many new methods have been proposed in recent years as alternatives to conventional upper gastrointestinal endoscopy for the diagnosis of oesophageal varices non-invasively or with minimum intervention. Out of them, 3 of these methods (the platelet count / spleen diameter ratio, fibro test and fibro scan) are truly non-invasive. Of these, the former is promising and needs validation. ${ }^{4}$

\section{METHODS}

After approval from the Institutional Ethical Committee this cross-sectional study was conducted among patients diagnosed with portal hypertension in medicine department, Victoria and Bowring and Lady Curzon Hospital. Bangalore Medical College and Research Institute, Bengaluru.

\section{Sample Size}

50

$s S=\frac{\mathrm{Z}^{2} *(\mathrm{p}) *(1-\mathrm{p})}{\mathrm{C}^{2}}$

Where:

$\mathrm{Z}=\mathrm{Z}$ value $=1.96$

$\mathrm{p}=$ percentage picking a choice, expressed as decimal (.5

used for sample size needed).

$\mathrm{c}=$ confidence interval, expressed as decimal.

\section{Inclusion Criteria}

All patients aged 18 years and above diagnosed to have portal hypertension (the presence of ascites, splenomegaly, reduced portal flow mean velocity $<12 \mathrm{~cm} /$ second or the portal vein diameter $>13 \mathrm{~mm})^{5}$ using ultrasonography admitted to Victoria and Bowring and Lady Curzon hospitals.

\section{Exclusion Criteria}

1. Patients with hepatocellular carcinoma.

2. Previous or current treatment with beta blockers.

3. Patients with previous or current treatment with nitrates and diuretics.

4. Established cases of oesophageal varices with portal hypertension on treatment.

\section{Procedure}

Fifty patients with portal hypertension who were admitted to medicine ward were selected for the study after obtaining written informed consent. Unstable patients particularly with variceal bleeding were excluded from the study. Patients who were on primary prophylaxis or who had undergone definitive treatment for oesophageal varices or who presented with active gastrointestinal bleeding were excluded from the study. All patients underwent clinical examination and laboratory tests (Complete haemogram, liver function test, ultrasound abdomen and upper gastrointestinal endoscopy). Child Pugh score was calculated for all patients. In all patients an upper gastrointestinal endoscopy and an ultrasound of the abdomen was done to measure the maximum spleen bipolar diameter and to look for signs of portal hypertension (splenomegaly, ascites). The endoscopies were performed in a single endoscopy unit using a video endoscope. The spleen diameter, platelet count, and Platelet Count / Spleen Diameter (PC / SD) 
ratio were compared between the two groups of patients with and without oesophageal varices.

\section{Statistical Analysis}

Statistical analysis was done using SPSS for determining the association of various clinical, laboratory and ultrasonographic variables with the presence of varices was performed using Student's ' $\mathrm{t}$ ' test for continuous variables and chi-square test for categorical variables. The $p$ values $<0.05$ were considered statistically significant. For the purpose of the study patients were classified to two groups, those with varices and those without varices. Sensitivity and specificity, positive and negative predictive values were computed and reported for PC / SD ratio. The Receiver Operating Characteristic (ROC) curve was applied to determine the cutoff values with best sensitivities and specificities for PC / SD ratio.

\section{RESULTS}

\begin{tabular}{|c|c|c|c|c|}
\hline Parameter & $\begin{array}{l}\text { Varix Absent } \\
(n=13) \\
\text { Mean }+/- \text { SD }\end{array}$ & $\begin{array}{c}\text { Varix Present } \\
\quad(n=37) \\
\text { Mean }+/- \text { SD }\end{array}$ & $\begin{array}{c}P \\
\text { Value }\end{array}$ & $\begin{array}{c}\text { Signific } \\
\text { ance }\end{array}$ \\
\hline Age & $52.77+/-10.70$ & $46.30+/-11.99$ & $>0.05$ & NS \\
\hline Serum Albumin & $3.0615+/-0.698$ & $2.695+/-0.565$ & $>0.05$ & NS \\
\hline $\begin{array}{l}\text { Serum } \\
\text { Bilirubin }\end{array}$ & $3.762+/-2.877$ & $5.403+/-5.551$ & $>0.05$ & NS \\
\hline SGOT & $40.846+/-16.767$ & $55.865+/-37.383$ & $<0.01$ & HS \\
\hline SGPT & $40.615+/-17.246$ & $43.047+/-28.093$ & $>0.05$ & NS \\
\hline Haemoglobin & $10.47+/-1.405$ & $9.673+/-2.371$ & $>0.05$ & NS \\
\hline INR & $2.46+/-0.776$ & $1.6140+/-0.575$ & $>0.05$ & NS \\
\hline $\begin{array}{l}\text { Child Pugh } \\
\text { Score }\end{array}$ & $2.46+/-0.776$ & $3.514+/-0.651$ & $<0.01$ & HS \\
\hline Platelet count & $\begin{array}{c}148538.46+/- \\
39331.106\end{array}$ & $\begin{array}{c}117972.97+/- \\
57807.384\end{array}$ & $<0.05$ & $\mathrm{~S}$ \\
\hline $\begin{array}{c}\text { Spleen } \\
\text { diameter }\end{array}$ & $118.22+/-13.65$ & $138.32+/-17.78$ & $<0.01$ & HS \\
\hline $\mathrm{PC} / \mathrm{SD}$ ratio & $\begin{array}{c}1275.04+/- \\
401.761\end{array}$ & $890+/-551.888$ & $<0.01$ & HS \\
\hline & $\begin{array}{r}\text { 1. Relationsh } \\
\text { and Pre }\end{array}$ & $\begin{array}{l}\text { tween } \mathrm{Lab} \mathrm{Pa} \\
\text { e of Varices }\end{array}$ & tel & \\
\hline
\end{tabular}

This table represents the relationship between parameters like age, serum albumin, serum bilirubin, SGOT (Serum Glutamic-Oxaloacetic Transaminase), SGPT (Serum GlutamicPyruvic Transaminase), haemoglobin, INR (International Normalised Ratio), Child-Pugh score, platelet count, spleen diameter and PC / SD ratio with presence of varices. NS-Not Significant, HS-Highly Significant.

\begin{tabular}{|cccc|}
\hline Platelet Count & Varix Absent & Varix Present & Total \\
$21000-50000$ & 0 & 3 & $\mathbf{3}$ \\
$51000-99000$ & 2 & 12 & $\mathbf{1 4}$ \\
$100000-150000$ & 6 & 16 & $\mathbf{2 2}$ \\
$>150000$ & 5 & 6 & $\mathbf{1 1}$ \\
Total & $\mathbf{1 3}$ & $\mathbf{3 7}$ & $\mathbf{5 0}$ \\
\hline Table 2. Comparison between Platelet Count and Presence of Varices \\
\hline This table compares the severity of thrombocytopenia with presence of varices \\
\hline
\end{tabular}

Patients were categorized in two groups based on cut off value of 909 for platelet count / spleen diameter ratio. A significant difference between the presence or absence of oesophageal varices and platelet count to spleen diameter ratio of $<909$ was observed.

- Sensitivity - $68 \%$

- $\quad$ Specificity - $92 \%$
- $\quad$ Positive predictive value - $96 \%$

- $\quad$ Negative predictive value - $50 \%$

The sensitivity of PC / SD ratio of 909 in predicting varices is $68 \%$ and specificity is $92 \%$.

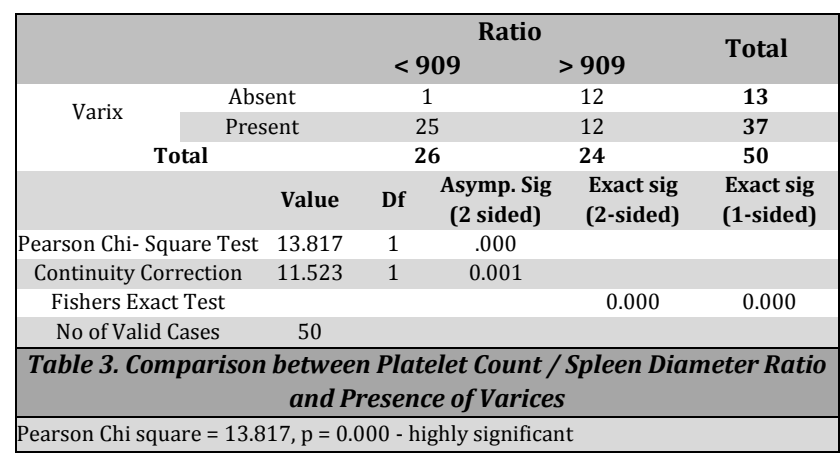

\begin{tabular}{|c|c|c|c|c|}
\hline & & \multicolumn{2}{|c|}{ Ratio } & \multirow[b]{2}{*}{ Total } \\
\hline & & $<909$ & $>909$ & \\
\hline \multirow{5}{*}{ Grade } & Absent & 1 & 12 & 13 \\
\hline & Grade 1 & 5 & 7 & 12 \\
\hline & Grade 2 & 10 & 4 & 14 \\
\hline & Grade 3 & 7 & 1 & 8 \\
\hline & Grade 4 & 3 & 0 & 3 \\
\hline \multicolumn{2}{|c|}{ Total } & 26 & 24 & 50 \\
\hline \multicolumn{5}{|c|}{ Chi Square Test } \\
\hline \multirow{2}{*}{\multicolumn{2}{|c|}{ Pearson Chi-Square }} & Value & df & Asymp. SIG (2-SIDED) \\
\hline & & 29.664 & 4 & 0.001 \\
\hline \multicolumn{2}{|c|}{ Likelihood Ratio } & 23.103 & 4 & 0.000 \\
\hline \multicolumn{2}{|c|}{ No. of Valid Cases } & 50 & & \\
\hline \multicolumn{5}{|c|}{$\begin{array}{c}\text { Table 4. Comparison between Platelet Count / Spleen Diameter Ratio } \\
\text { and Grade of Varices }\end{array}$} \\
\hline
\end{tabular}

\section{DISCUSSION}

Oesophageal varices were noted in approximately $40 \%$ of patients with early cirrhosis and in $60 \%$ of those with portal hypertension.6,7 The incidence of gastrointestinal bleeding is 1 to $2 \%$ per year in patients without oesophageal varices, $5 \%$ in those with small oesophageal varices and $15-20 \%$ in those with large oesophageal varices annually. ${ }^{6}$ In an attempt to decrease the burden of endoscopic units, many studies have been performed to identify the parameters that can predicts oesophageal varices non-invasively in patients with liver cirrhosis. ${ }^{8}$

The management of patients with liver cirrhosis has advanced over the past few decades has led to improved survival.9,10 However, the cause of death in patients with portal hypertension remains ruptured oesophageal varices, with a mortality rate of up to $11-16 \%$ within 6 weeks after a bleeding episode. ${ }^{9}$ Thus, prevention of variceal bleeding should be an important goal. The first crucial step is to identify the patients at risk of bleeding from oesophageal varices by initiating prophylactic treatment. It is known that prevalence of varices is higher in decompensated cirrhosis than compensated cirrhosis and that; large oesophageal varices and initiate have higher chance of presenting as a bleed than small oesophageal varices. ${ }^{11}$

The reported prevalence of varices in compensated cirrhosis is varied, ranging from $24 \%$ to $80 \%{ }^{11}$ Diagnosing the presence of oesophageal varices using non-invasive methods will decrease the use of endoscopy in patients with high probability of having varices. 
Several studies $8,12,13$ have concluded that the platelet count and spleen diameter correlate well with the presence of oesophageal varices. However, in patients with cirrhosis low platelet count depends on several other factors like decreased mean platelet lifetime, direct myelotoxic effect of alcohol, decreased thrombopoietin production or hepatitis virus. Presence of enlarged spleen is likely the result of vascular disturbances that are mainly related to portal hypertension.

Giannini et $\mathrm{al}^{7}$ attempted to devise a new parameter that could be more consistent with non-invasive diagnosis of oesophageal varices in cirrhotic patients. The parameter links thrombocytopenia to splenomegaly to introduce a variable that takes into account the reduced platelet count most likely attributed to hypersplenism caused by portal hypertension. ${ }^{14}$ Several studies ${ }^{13,15,16}$ have been attempted to validate this new parameter as a screening tool to predict the presence of oesophageal varices. The study by Giannini et $\mathrm{al}^{8}$ incorporated the PC / SD with interesting results (100\% sensitivity and 77 $\%$ specificity). The current study focused on parameters associated with presence of varices. The variables included were most relevant parameters detected in previous studies.

Our study sample consisted of 50 patients of whom 42 were males and 8 were females. Mean age for females was 50 + / - 8.97. Mean age for males was $47.6+$ / - 12.44. Overall mean age was $47.98=/-11.91$. Patients were grouped into different age groups from 20 years onwards. The youngest patient in our study was 24 years old and oldest was 70 years. In our study $34 \%$ were in the age group of 31 - 40 years. Males predominated in each of the age group studied.

Among the 50 patients of cirrhosis studied 37 (74\%) had oesophageal varices. Varices were graded into 4 grades according to the severity. Distribution of the cases in shown in the table according to the variceal grading. Grade 1 and grade 2 predominated in our study.

Most of the patients had cirrhosis secondary to ethanol abuse. Three patients had serology positive for Hepatitis B but were also alcoholics. When compared to similar studies the aetiology in our study was in gross contrast to other studies with alcohol implicated in $90 \%$ of patients because of the small study sample and limitation of the laboratory facilities.

Presence of ascites was determined clinically and radiologically by ultrasound examination. Ascites was found in 36 patients $(72 \%)$. It correlated with presence of varices with $\mathrm{p}$ value of $<0.01 \%$. Encephalopathy was noted in 10 patients in our study. Significant correlation was noted in patients with encephalopathy and presence of varices. It also correlated significantly with the grade of varices.

Univariate analysis was conducted on laboratory and ultrasonography data and PC / SD ratio which are continuous variables using the Student's ' $\mathrm{t}$ ' test. The variables which were significant between the two groups were haemoglobin ( $p<$ 0.01), SGOT ( $p<0.01)$, Child Pugh score $(p<0.01)$, platelet count $(\mathrm{p}<0.05)$, spleen diameter $(\mathrm{p}<0.01)$ and PC / SD ratio $(\mathrm{p}<0.01)$.

Mean platelet count in patient without varices was $148538.46+/-39331.106$ and in patients with varices was $117972.97+/-57807.384$. Significant statistical difference was noted in two groups of patients $(p<0.05)$. However, the severity of thrombocytopenia did not correlate well with presence of varices. There are several other studies which similarly concluded that platelet count alone is inadequate for predicting the occurrence of gastroesophageal varices in cirrhosis.

In our study mean spleen diameter was significantly different between the two groups ( $p$ 0.01) with mean of $138+$ / - 17.78 in patients with varices and $118.22+/-13.65$ in those without varices. Platelet count / spleen diameter ratio has been shown to correlate well with the presence of varices and several other studies have been performed to validate this new parameter. The mean PC / SD ratio was significantly different in the two groups of patients $(p<0.01)$. Performance characteristic of PC / SD was noted for various study designs. In our study deriving from the ROC curve PC / SD ratio with best sensitivity and specificity was 1062 . When the cut off value for PC / SD was taken as 1062 specificity was $78 \%$ and sensitivity was $78.37 \%$. The positive predictive value was 87.87 and negative predictive value was $57.94 \%$. However, the accuracy of predicting oesophageal varices need to be confirmed with randomized control trials.

\section{CONCLUSIONS}

PC / SD ratio apart from being a non-invasive test, is also cost effective and is not associated with a steep learning curve as required for invasive diagnostic procedures. Evidence is not good enough to replace endoscopy as a screening tool for detecting oesophageal varices in patients with portal hypertension. It is useful in situations where endoscopy is not feasible or not available for guiding the clinician in the management of patients with cirrhosis and in preventing complications.

Data sharing statement provided by the authors is available with the full text of this article at jemds.com.

Financial or other competing interests: None.

Disclosure forms provided by the authors are available with the full text of this article at jemds.com.

\section{REFERENCES}

[1] Maruyama H, Sanyal AJ. Portal hypertension: non-surgical and surgical management. In: Schiff L, Schiff E, eds. Diseases of the liver. $11^{\text {th }}$ edn. Wiley-Blackwell Publication 2011.

[2] Sarangapani A, Shanmugam C, Kalynasundaram M, et al. Non-invasive prediction of large esophageal varices in chronic liver disease patients. Saudi J Gastroenterol 2010;16(1):38-42.

[3] Bacon BR. Cirrhosis and its complications. Chap - 408. Harrison's Principles of Internal Medicine. $18^{\text {th }}$ edn. McGraw-Hill Publication 2012.

[4] Shah VH, Kamath PS. Portal hypertension and gastrointestinal bleeding. Chap - 90. Slesinger and Fordtran's Gastrointestinal Liver Disease. 9th edn. Elsevier Publication 2010.

[5] Berzigotti A, Seijo S, Reverter E, et al. Assessing portal hypertension in liver diseases. Expert Rev Gastroenterol Hepatol 2013;7(2):141-55.

[6] D' Amico G, Luca A. Natural history. Clinicalhemodynamics correlations. Prediction of the risk of 
bleeding. Baillieres Clin Gastroenterol 1997;11(12):24356.

[7] Freeman JG, Darlow S, Cole AT. Platelet count as a predictor for the presence of oesophageal varices in alcoholic cirrhotic patients. Gastroenterology 1999;116:A1211-71.

[8] Giannini E, Botta F, Borro P, et al. Platelet count / spleen diameter ratio: proposal and validation of a non-invasive parameter to pedict the presence of esophageal varices in patients with liver cirrhosis. Gut 2003;52(8):1200-5.

[9] D’Amico G, De Franchis R. Upper digestive bleeding in cirrhosis: post- therapeutic outcome and prognostic indicators. Hepatology 2004;38(3):599-612.

[10] D'Amico G, Garcia-Tsoa G, Cales P, et al. Diagnosis of portal hypertension: how and when? Portal hypertension III. In: De Franchis R, ed. Proceedings of the Third Baveno International Consensus Workshop on Definitions, Methodology and Therapeutic Strategies. Oxford: Blackwell Science 2001: p. 36-63.

[11] Abbasi A, Butt N, Bhutto AR, et al. Correlation of thrombocytopenia with grading of esophageal varices in chronic liver disease patients. J Coll Physicians Surg Pak 2010;20(6):369-72.

[12] Madhotra R, Mulcahy HE, Willner I, et al. Prediction of esophageal varices in patients with cirrhosis. J Clin Gasteroenterol 2002;34(1):81-5.

[13] Burton JR, Liagpunsakul S, Lapidus J, et al. Validation of a multivariate model predicting presence and size of varices. J Clin Gastroenterol 2007;41(6):609-15.

[14] Torres E, Calme F, Herrera B. Echographic parameters in the evaluation of the degree of portal hypertension. Rev Gastroenterol Peru 1996;16(2):125-32.

[15] Giannini EG, Botta F, Borro P, et al. Application of the platelet count / spleen diameter ratio to rule out the presence of esophageal varices in patients with cirrhosis: a validation study based on follow-up. Dig Liver Dis 2005;37(10):779-85.

[16] Baig WW, Nagaraja MV, Varma M, et al. Platelet count to spleen diameter ratio for the diagnosis of esophageal varices: Is it feasible? Can J Gastroenterol 2008;22(10):825-8. 